\title{
A Unified Analysis of English Passive Voice and Aspects
}

\author{
Benedictus B. Dwijatmoko \\ b.b.dwijatmoko@gmail.com \\ Sanata Dharma University \\ Indonesia
}

\begin{abstract}
English passive voice and aspects are generated in the same process and have the same Dstructure. In a passive sentence, progressive sentence, and perfect sentence, $\mathrm{T}$ (tense) takes a VP headed by be or have, and be or have takes a Participle Phrase (PartP), and -en or ingtakes a VP as its complement. Be or have in the upper VP merges with T, and the verb in the lower VP merges with Part. The specifier or complement of the lower VP moves cyclicly through the specifier of Part and the specifier of the upper verb to occupy the subject position. The single theory on the production of passive, progressive, and perfect sentences observes the principle of economy of derivation and, therefore, contributes to the explanation of the relative easiness of a child in acquiring his or her mother tongue.
\end{abstract}

Keywords: sentence, passive voice, progressive, perfect, D-structure

\section{Introduction}

English has a complex predicate system. Besides the tense, a sentence may have an auxiliary verb be and a verb in the past participle or -en form to show a passive voice, an auxiliary verb be and a verb in thepresentparticiple (progressive)or-ing form to show a progressive aspect, and the auxiliary verb have and a verb in the past participle or -en form to show a perfect aspect. Sentences (1) - (3) show the different predicate forms.

(1) The proposal was accepted.

(2) John is reading the book.

(3) John has returned my camera.

Sentence (1) - (3) are a passive sentence, a progressive sentence, and a perfect sentence respectively. They are different in the choice of the subject, the auxiliary verb, and the verbal affixes.

Both the passive voice and the progressive and perfect aspects have been discussed widely(Jaegli, 1986; Shibatani,
1988; Åfarli, 1989; Caponigro \& Schütze, 2003; Embick, 2004; Kallulli, 2007; Castillo, 2009; Kiparsky, 2013; Breul, 2004; Breul, 2014), though not exhaustively. The nature of the suffix -en and -ing and their presence in their D-structure has not been revealed well.

Chomsky(1986, p. 157) states that Dstrcuture was to be regarded as "a pure representation of theta-structure" without inflectional affixes which do not affect theta-marking and s-selection. In Radford (2004) and Haegeman(2006), the progressive aspect is marked with the verb be which takes a VP headed by an -ing form as its complement. A sentence in the progressive and perfect aspect is described as a sentence which has the aspect auxiliary verb have or be under $\mathrm{T}$ which in turn takes a VP headed a "specific kind of verb"(Radford, 2009, p. 252), namely a verb in the -en or -ing form. The verb be takes a 
V-ing to observe the selectional inflection -en in the passive voice and the inflection -ing for the progressive aspect have not been dealt sufficiently (Fleisher, 2006; Bruening B. , 2012).

The identification of a V-ing as the head of a VP which be selects does not reflect the nature of the suffix. The suffix ing, which is an inflectional suffix, functions at the syntactic level. Consequently, its position in the generation of a sentence with a progressive aspect needs to be displayed.

This article argues for a unified passive, progressive, and perfect analysis. In the unified analysis, a passive sentence, a progressive sentence, and a perfectsentence are genarated in the same process and have the same D-structure, and the participle inflections -en and -ing functions as a syntactic unit and form a Participle Phrases (PartP).

For the discussion of the structure of the three kinds of sentence, the structure of a sentence (4) as it is displayed in diagram (5) will be used.

(4) John wrote the paper. features(Radford, 2004). The nature of the

A sentence is analyzed as a complementizer phrase (CP) where $\mathrm{C}$ takes a Tense Phrase (TP) as its complement (Radford, 2004; 2009). In turn, $T$ takes a verb phrase (VP) as its complement. The suffix -ed is identified as Tense and not Inflection (I) because English verb suffixes can be -es and -ed, the tense markers, or -en the perfect and passive inflection and -ing, the progressive inflection.

Following the Internal Subject Hypothesis(Koopman \& Sportiche, 1991; McNally, 1992; Burton \& Grimshaw, 1992; Belliti, 2009; Koizumi \& Tamaoka, 2010), the subject of (4) John is generated as the specifier of the verb write and not the specifier of $\mathrm{T}$. As a head of a functional

(5)

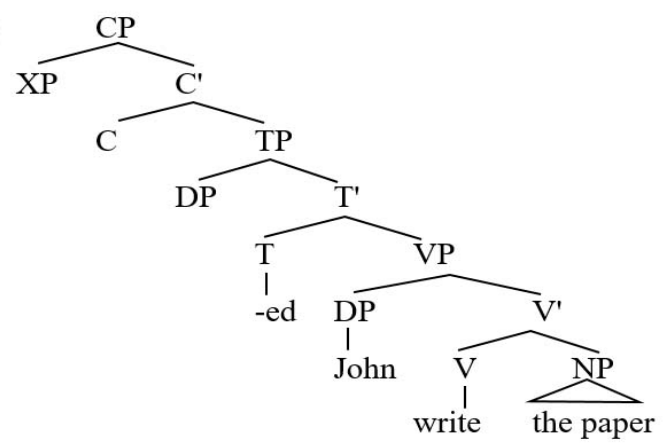

phrase, $\mathrm{T}$ does not require a specifier with certain semantic features. The NP like John in (4), which is [+human], on the contrary, is needed as a specifier of the verb write.

\section{The Participle}

English has four verbal inflections, namely the present tense marker -es, the past tense marker -ed, the passive voice and perfect aspect -en, and the progressive aspect -ing(Carstairs-McCarthy, 2002; Lieber, 2009). The tense inflections are more frequent and productive than the aspect inflections as every English sentence always requires a tense marker and only passive sentences and sentences which indicate a perfect or progressive aspect carry a participle inflection.
Although Part is less frequent than T, the status as an inflection brings a significantconsequence in the structure of the progressive and perfect aspects and the passive voice of English. According to Carstairs-McCarthy(1992)an inflection process occurs after a derivation process in a certain part of grammar,or an inflection process takes place at the syntactic level after a word is formed in the morphological level Anderson(1992). The principle can be clarified with sentences (6)-(8). 
(6) The minister has clarified the statement.

(7) The president is emphasizing the need for tolerance.

(8) The villagers were empowered by the meetings.

The verbs clarified, emphasizing, and empowered take Part after the stems clarify, emphasize, and empower are derived.

The derivation of clarify, emphasize, and empower from clear, emphasis, and power bring a significant change in the semantic features of the derived words. The derived verbs have a capacity to take two arguments; a capacity which the stems do not have. If Part is separated from the sentences and the auxiliary verbs are put aside first, a configuration like (9)-(11) will occur.

(9) -en [the minister clarify his statement]

(10) -ing [the president emphasize the need for tolerance]

(11) -en [the meetings empower the villagers]

The verbs clarify, emphasize, and empower have the capacity to hold two NPs in the VP. The preposition by in (11) is dropped because it is simply inserted in the formation of the S-structure to assign Case to the noun phrase the meetings.

The NPs in (9)-(11) belong to the bracketed strings because their presence is needed by the derivation affixes -ify, -ize, and $\mathrm{em}$ - respectively. They would not be there if the roots clear, emphasis, and power were there instead of the derived verbs. The arguments in (9)-(11), therefore, form phrases which are headed by clarify, emphasize, and empower respectively. The bracketed strings are obviously VPs.

The derived verbs clarify in (9) semantically (s-)selects the minister and the statement as its arguments, emphasize in (10) s-selects the president and the need for tolerance and the president, and empower in (11) s-selects the meetings and the villagers. The arguments in each number enter the configuration in different levels with his statement, the need for tolerance, and the villagers being closer to clarify, emphasize, and empower than the arguments the minister, the president, and the meetings respectively. Thus, only the X-bar theory can capture the relationships of the VPs. The structure of the VP in (9) can be displayed in diagram (12) below.

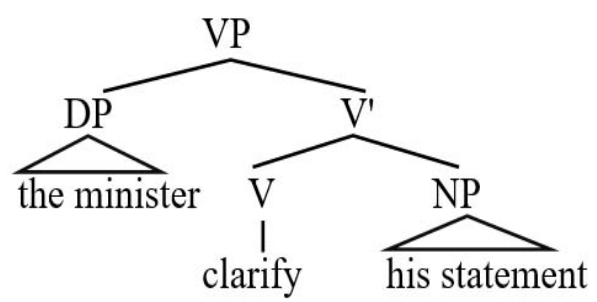

The VPs the president emphasize the need for tolerancein (10) and the meetings empower the villagers in (11) have the same structure as (12).

As the structure of the VPs of (9) - (11) are set, what remains to determine is the relation of the VPs with Part. Part in (9) (11) is obviously not a part of the VPs and is outside the VPs. V does not take Part, but, on the contrary, Part takes VP. Part is similar to $\mathrm{T}$ in that Part and $\mathrm{T}$ are both inflections. If $\mathrm{T}$ takes a $\mathrm{VP}$ as its complement, Part also takes VP as its complement and forms a phrase, namely a PartP. As both $\mathrm{T}$ and Part are bound morphemes which cannot occur by itself in a sentence, they both take a phrase which is headed by a lexical item as their complement. Then Part absorbs and merges with the lexical head. The structure of (6) can, thus, be displayed in (13). 
(13)

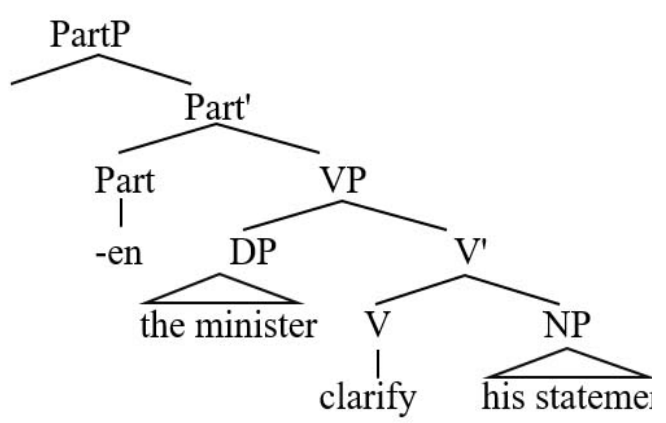

PartP (10) and (11) have the same structure as PartP (9).

Part is similar to $\mathrm{T}$ in Case assignment. According to Case theory (Chomksy, 1981; Koopman \& Sportiche, 1991; Haegeman, 2006; Radord, 2004; 2009), every argument in a sentence should be assigned Case to occur legitimately.

(14) John wrote the paper in three weeks.

(15) The paper was written by John in three weeks.

In (14) the argument John is caseassigned by $-e d$, and in (15) John is caseassigned by the preposition by. With the PP in three weeks neglected, the stucture of (14) can be displayed in diagram (16).

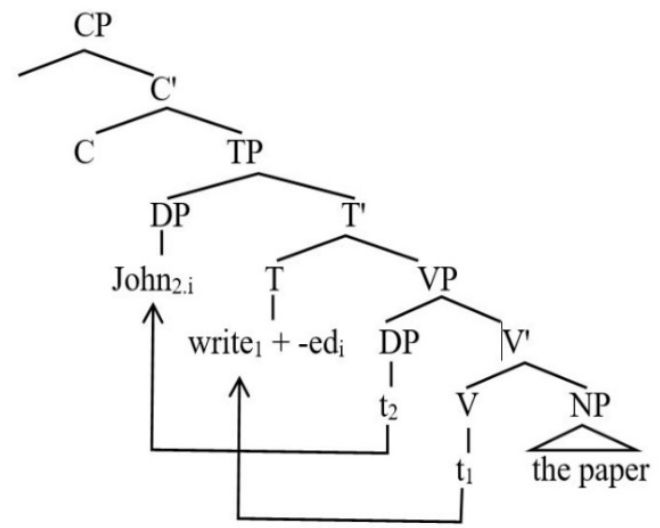

The case-assignment in (14) occurs under two conditions, namely co-indexing and m-command. John can be co-indexed with -ed without breaking any grammatical rule, and John is also m-commanded by -ed. The maximal projection which dominates John also dominates -ed.
A similar case assignment also occurs in a non-finite clause with a subject.Quirk et al.(1972)identify that a non-finite verb can occur without a subject or with a subject like in (17)-(20).

(17) His hands handcuffed, the criminal was brought to court.

(18) All his money spent, the young man had nothing to eat.

(19) Her kids going to school, Mrs. Smith has more time for herself.

(20) The workers working late, Diana could not go home early.

The subject of the non-finite predicates in (17) - (20) are his hands, all his money, her kids, and the workers respectively. The argument his hands in (17) and all his moneyin (18) are case-assigned by Part -en, and the arguments her kids in (19) and the workers in (20) are case-assigned by Part ing. Part -en in (17) and (18) and -ing in (19) and (20) are the only potential case-assigner. No element in [vP(sb) handcuff his hands], [vp $(s b)$ spend all his money], [vphis kids go to school], and [vpthe workers work late] assign a case. The arguments have to move to the specifier of -en or -ing to get a case.

PartP in (17) and (18) have the same structure. The structure of (17) can be displayed in diagram (21).

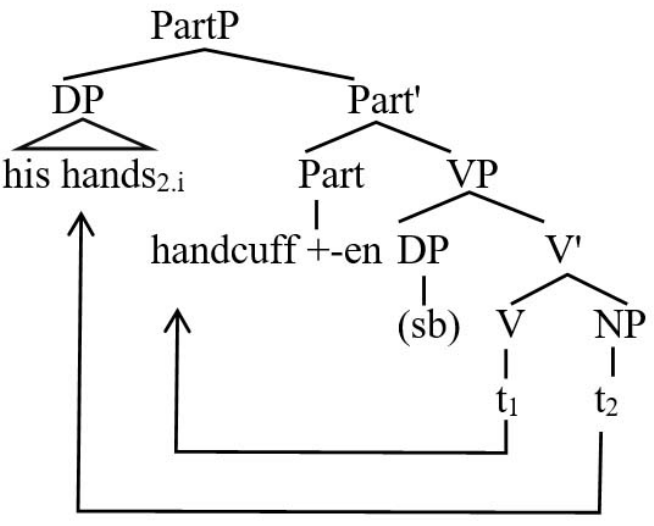

The PartP in (17) is base-generated as in (21). The verb handcuff, then, merges with en because -en is a bound morpheme; it 
absorbs handcuff to meet the morpholoical requirement that a bound morpheme should be attached to a stem. His handsmoves from the Spec/V position to the Spec/Part position to be case-assigned. PartP in (18) has the same D-structure and processes as (21).

PartPs in (19) and (20) have a similar elements and process. The difference lies in the presence of the progressive aspect affix ing and in the VPs. The Vs are intransitive and only has Spec/V. His kids and the workers move to Spec/Part to be caseassigned, and go and work merge with -ing to form going and working.

The assignment of the nominative case in Indonesian works in the same as in English. Indonesian verbal sentences does not have agreement between the subject and predicate, and the only potential nominative case assigner is the Voice Affix meng$\left(\mathrm{Vc}_{\mathrm{Act}}\right)$ or di- $\left(\mathrm{Vc}_{\mathrm{Pas}}\right)$ like in (22) and (23).

(22) Ibu mem-baca buku saya mother $\mathrm{Vc}_{\mathrm{A}}$ read book I 'Mom read my book.'

(23) Buku saya di- baca ibu. book I $\mathrm{Vc}_{\mathrm{P}}$ read mother 'My book was read by Mom.'

(24) Surat itu tidak ter-baca olehku letter the not $\mathrm{V}_{\mathrm{CP} / \mathrm{abl}}$ read by-me 'I cannot read the letter.'

$I b u$ 'mother' in (22) is assigned a nominative case by $\mathrm{Vc}_{\mathrm{Act}}$, and buku saya 'my book' is assigned a nominative case by $\mathrm{Vc}_{\text {Pas. }}$. The diagram of VcP (22) can be shown in diagram (25).

\section{The Auxiallary Verb be and have}

The verb be occurs with a verb in the -en form to show the passive voice like in (1) and with a verb in the -ing form to show the progressive aspects like in (2). The verb have occurs with the -en form. The
(25)

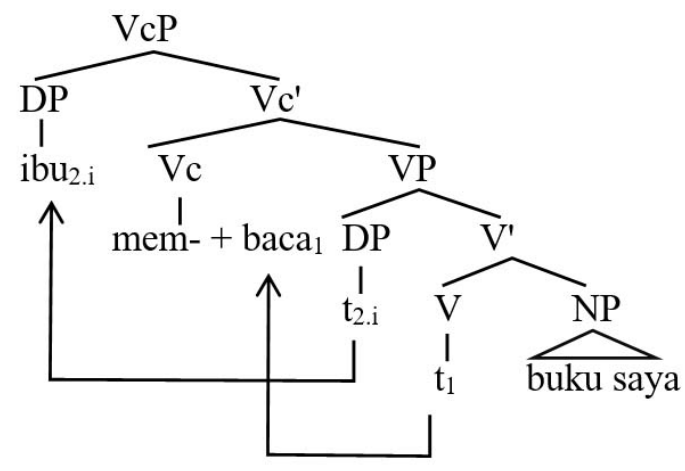

$\mathrm{V}$ baca 'read' merges with meng- to form the active formmembaca 'to read'. Then, ibu 'mother' moves to Spec/Vc to be assigned a nominative case by meng-. The passive sentence (23) and (24) has the same D-structure and syntactic processes as (22) except that Vc is $d i$ - in (23) and Vc in (24) is a passive with the ability meaning.

To sum up the discussion on Part, it can be said that English participles -en and -ing have the same status as an inflection which heads a phrase. It forms a phrase (PartP), it takes a VP as its complement, and it also assigns a nominative case. Consequently, with the status of Part as a head of PartP, a verb in the -en and -ing form does not enter the generation of a passive, perfect, or progressive sentence as a stem+-en or stem+-ing form, but as stem form. A stem+en form and stem+-ing form result in as process of merging $\mathrm{V}$ with Part.

From the discussion of the derived verbs clarify, emphasize, and empower, it can also be said that the three-level analysis of VP is internally motivated. The structure of a VP with a head like clarify, emphasize, and empower can only be explained with the $\mathrm{X}$-bar theory.

occurrence of be with verb in the -en form and -ing form in (1) and (2) respesctively and the occurrence of have with a verb in the -en form like in (3) may only show one of the fuctions of the auxiliary verbs. The 
auxiliary verbs also occur with several different forms of verbs of constructions.

The auxiliary verb be occurs with different phrase categories in (26) - (30).

(26) (a) John is very helpful.

(b) John is [AP very helpful].

(27) (a) John is a good student.

(b) John is [NP a good student].

(28) (a) John is in the library.

(b) John is [pp in the library].

(29) (a) John is to do the decoration.

(b) John is [тР to do the decoration].

(30) (a) The problem is that the workers often came late.

(b) The problem is [ ${ }_{\mathrm{CP}}$ that the workers often came late].

The verb be occurs with anAP in (26), an NP in (27), a PP like in (28), a CP headed by that like in (29), and a TP headed by to in (30).

The analysis of TP as the complement of be in (29) follows the theory that TP or IP can be headed by a modal like can, may, and must, -es or -ed, and to. The complement of the verb want in (31) and plan in (32) is, then, also TP.

(31) (a) John wants to go to the movie.

(b) John wants [TP to go to the movie].

(32) (a) Ricky plans to finish his study in July.

(b) Ricky plans [тр to finish his study in July].

The complement of be in (1) and (2), which are rewritten as (33) and (34) below, is, therefore, also PartP.

(33) The proposal was accepted.

(34) John is reading the book.

Part as the head of PartP, then, takes a VP as its complement. The structure of the VP with be as the head in (33) can be displayed in (35).
(35)

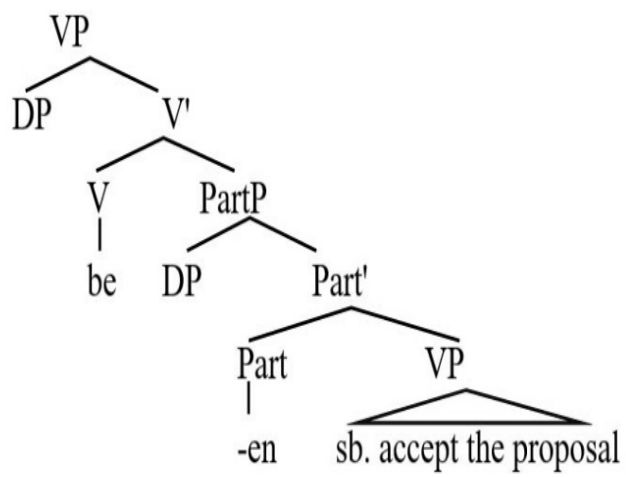

The VP with be as the head in (34) has the same structure as (35) except that Part is ing and the VP is [vP John read the book].

The auxiliary verb have also occurs with different phrase categories like in (36) (38).

(36) (a) John has a problem.

(b) John has [NP a problem].

(37) (a) John has to submit his work by Friday.

(b) John has [тр to submit his work by Friday].

(38) (a) John has his employees work for eight hours a day.

(b) John has [CP his employees work for eight hours a day].

The verb have has an NP as its complement in (36), a TP headed by to in (37), and a VP in (38). The status of NP as a complement of have is clear, and the status of $\mathrm{TP}$ as a complement of have can be understood from the status of to before an infinitive verb. To before an infinitive verb is Infl with a [Tense] feature (Chomsky, 1981) or simply $\mathrm{T}$ in later literature on generative grammar (Breul, Focus Structure in Generative Grammar: An Ingrated Syntactic, Semantic and Intonational Approach, 2004; Epstein \& Seely, 2006; Baker, 2008; Roy, 2013).

The status of VP as the complement of have in (38) can be compared with a VP which becomes the complement of the verb see in (39) and hear in (40).

(39) (a) I saw Danny take the camera.. 
(b) I saw [vp Danny take the camera].

(c) I saw him take the camera.

(40) (a) I heard Brian lock his door.

(b) I heard [vp Brian lock his door].

(c) I heard him lock his door.

In (39), Danny and the camera form a VP with the verb take as the head, and in (40) the NPsBrian and his door form a VP with the verb lock as the head.

With the capability of the verb be and have to take different phrase categories as its complement, it can also be concluded that be in (7) and (8) and have in (6), which are rewritten below as (41a) - (42a) also take PartP as its complement.

(41) (a) The villagers were empowered by the meetings.

(b) $\left[\mathrm{vP}\left[\mathrm{v}^{\prime}\right.\right.$ be PartP $[$ Part'-en $[\mathrm{vp}$ the meetings empower the villagers]]]]]

\section{The Structure of Passive, Progressive, and Perfect Sentences}

As is obvious from the discussion so far, a passive sentence and a progressive sentence, and a perfect sentence are produced with a series process of complementation. The same as any other sentence, a passive, progressive, and perfect sentence is a $\mathrm{CP}$, and $\mathrm{C}$ takes a TP as its complement, and what makes the three
(42) (a) The president is emphasizing the need for tolerance.

(b) $[\mathrm{vp}[\mathrm{v}$ ' be [PartP [Part'-ing [vp the president emphasize the need for tolerance]]]]]

(43) (a) The minister has clarified his statement.

(b) $\left[\mathrm{vP}\left[\mathrm{V}^{\prime}\right.\right.$ have $[$ PartP $[$ Part'-en $[\mathrm{vP}$ the minister clarify his statement]]1]]

The structure of (41a) - (43a) are displayed in $(41 b)-(43 b)$ respectively. The auliary verb be or have takes a PartP headed by -en or -ing to show a passive voice, a progressive aspect, or a perfect aspect. Then, Part takes a VP as its complement. As Part is a bound morpheme, it absorbs the head of the VP and merges with it.

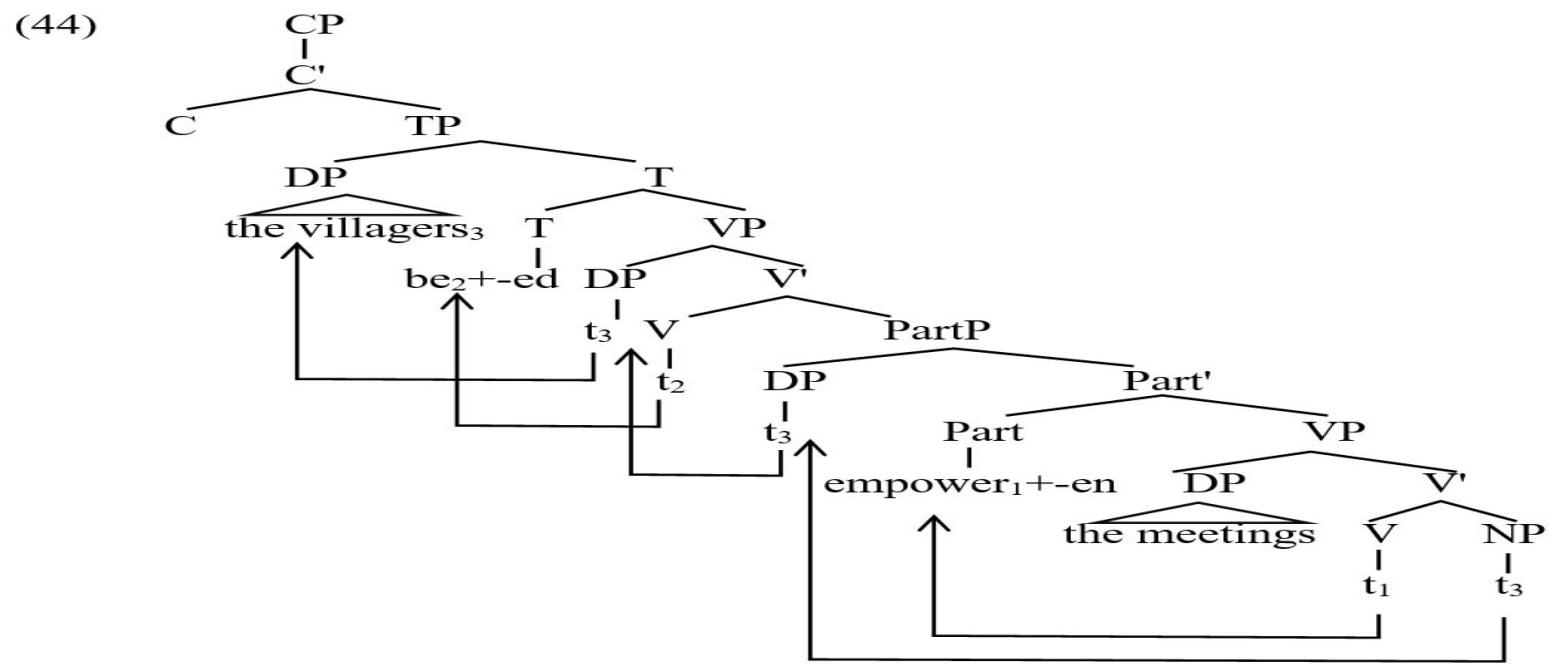


As seen in (44), in the D-structure-edtakes a VP headed by be, be takes PartP headed by -ento show the passive voice, and -en takes VP the meetings empower the people. The suffix -ed absorbs and merges with be to form were, and the suffix-en absorbs and mergers with empower to form empowered.

The subject of (44), the villagers, is base-generated as Comp/V and moves(b) cyclicly to the position of Spec/T. The NP first moves to Spec/Part first, then $48 \phi$ $\mathrm{Spec} / \mathrm{V}$, and finally to $\mathrm{Spec} / \mathrm{T}$. The $(\mathrm{b})$ movement of the NP to the Spec/Part is supported with sentences like (17) and (18), which are rewritten as (45a) and (46a).

(45)(a) His hands handcuffed, the criminal was brought to court.

(b) $\left[\right.$ PartP his hands $\left[\right.$ Part' - en $\left[\mathrm{vP}(\mathrm{sb})\left[\mathrm{v}^{\prime}\right.\right.$ handcuff $\left.\mathrm{t}_{1}\right]$

(46)(a) All his money spent, the young man had nothing to eat.

(b) $[$ PartP all his money 1 [Part' - en $[\mathrm{vP}$ (the young man) [ $\mathrm{v}^{\prime}$ spend $\mathrm{t}_{1}$ ]

As can be seen in the non-finite clause of (45a) and (46a), his hands and all his money are base-generated as the complement of handcuff and spend respectively. The two arguments move to Spec/Part to be caseassigned. Spec/Part is a legitimate position for an argument.

The specifier position of be is also a legitimate position for an argument. It can be seen in (47) and (48).

(47)(a) I cannot see the team be defeated.

b) I cannot see $\left[v p\right.$ the team ${ }_{1}\left[v^{\prime}\right.$ be $\left[\right.$ PartP $_{1} t_{1}$ Part en [vp $(\mathrm{sb})$ defeat $\left.\left.\left.\left.\left.\mathrm{t}_{1}\right]\right]\right]\right]\right]$

(a) You have to make your voice be heard.

) You have to make [vp your voice ${ }_{1}\left[\mathrm{v}^{\prime}\right.$ be $[$ PartP $\mathrm{t}_{1}$ [Part -en [vp $(\mathrm{sb})$ hear $\mathrm{t}_{1}$ ]]]]]

In (47), the argument the team is basegenerated as the complement of defeat, and then it moves to the Spec/Part position and finally to Spec/be. Similarly, in (48) the argument your voice is base-generated as the complement of hear, and then it moves to $\mathrm{Spec} / \mathrm{P}$ and finally to Spec/be.

A progressive sentence has the same structure as a passive sentence. The progressive sentence (42a), rewritten below as (49), can be displayed in (50).

(49) The president is emphasizing the need for tolerance.

(50)

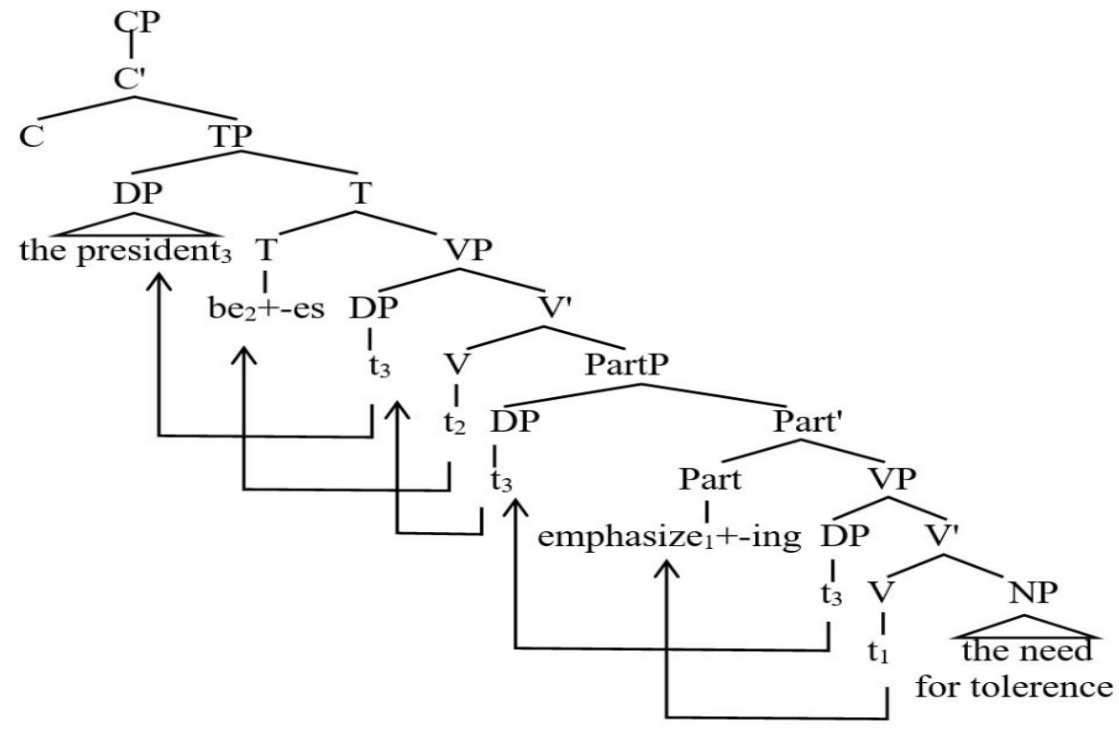

In (50), $\mathrm{T}$ takes a VP headed by be as its complement, and be takes PartP headed-ing to show the progressive meaning. $\mathrm{T}$ as a bound morpheme absorbs be and merges 
with it forming is. Part-ing takes a VP headed by emphasize. Then, it absorbs emphasize and merges with it, forming emphasizing.

The verb emphasize has the argument the president as $\mathrm{Spec} / \mathrm{V}$ and the need for tolerenceas Comp/ $\mathrm{V}$. As it is not a passive sentence, the Spec/V the president moves cyclicly to the Spec/T position. First, it moves to the Spec/Part position, to the $\mathrm{Spec} /$ be position, and finally to the $\mathrm{Spec} / \mathrm{T}$ to become to the subject of the sentence.

The movement of the president to its final position at the $\mathrm{Spec} / \mathrm{T}$ is legitimate. The first landing-site of the argument, Spec/Part, is a legitimate position. The argument her kids in the non-finite clause of (51) and the workers in the non-finite clause of (52) also occupy the Spec/Part position.

(51) (a) Her kids going to school, Mrs. Smith has more time for herself. (b) $\left[\right.$ PartP her kids [Part' - ing $\left[\mathrm{vP} \mathrm{t}_{1}\left[\mathrm{v}^{\prime}\right.\right.$ go to school]]]]

(52) (a) The workers working late, Diana could not go home early.

(b) $\left[\right.$ PartP the workers ${ }_{1}\left[\right.$ Part' $^{-}$-ing [vp $\mathrm{t}_{1}$ [ $\mathrm{V}^{\prime}$ work late]

As can be seen in (51), her kids is basegenerated as Spec/go and moves to Spec/Part, and in (50) the workersis basegenerated as Spec/work and moves to Spec/Part as well. The movement of the president from $\mathrm{Spec} / \mathrm{Part}$ to $\mathrm{Spec} / b e$ is also legitimate. As sentences (51) and (52) show, Spec/be can be occupied by an argument.

A perfect sentence has the same structure as a passive sentence and progressive sentence. The structure of (43), rewritten below as (53), can be displayed in diagram (54).

(53) The minister has clarified his statement.

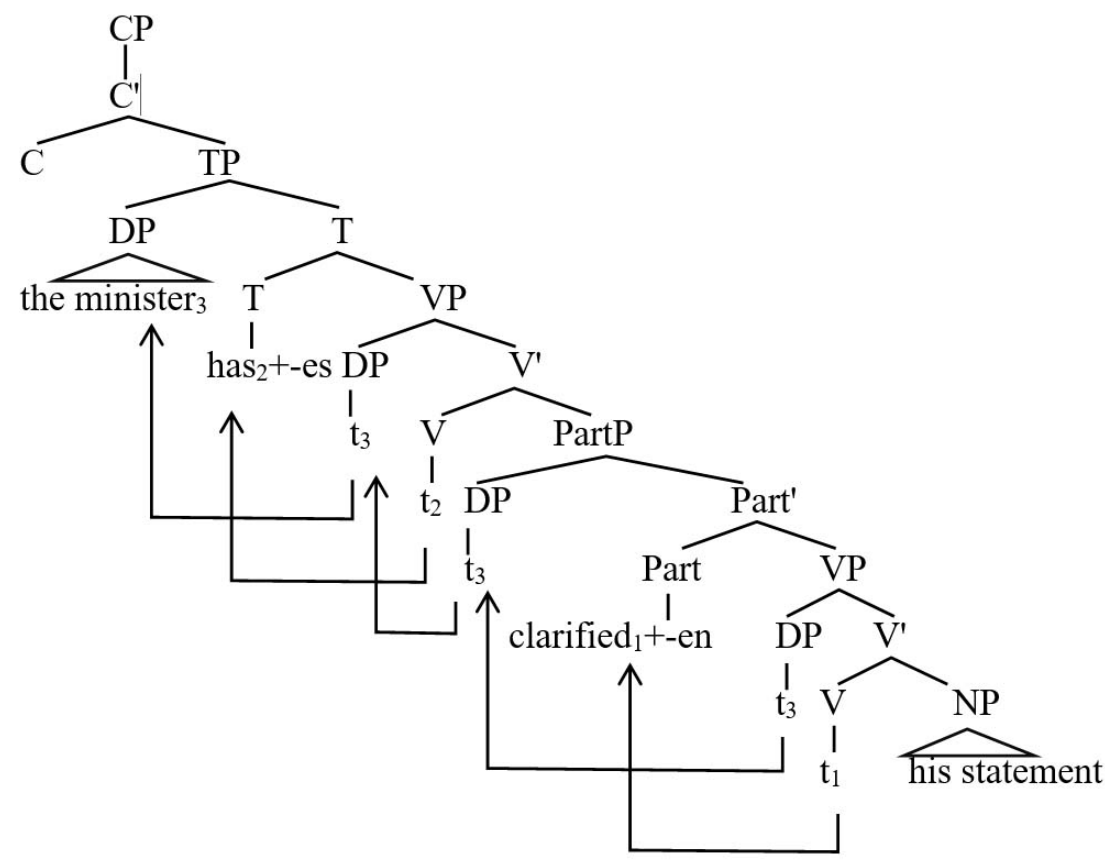

The sentence has -es as the head of TP. The inflection takes a VP headed by have as its complement. The inflection, then, absorbs and merges with have to form has in agreement with Spec/T. Have takes a PartP headed by -en, which, in turn, takes a VP headed by clarify. The Part -en, then, absorbs and merges with clarify forming clarified. 
The subject of (54) is base-generated as Spec/clarify. Then, it moves cyclicly to Spec/Part, Spec/have, and finally Spec/T. The movement is legitimate as the landingsite which it temporarily occupies is a position which an argument may occupy.

A sentence which has both a passive voice and progressive or perfect aspect or have both the perfect aspect and the progressive aspect contains two PartPs. Sentences (55) and (56) below have two PartPs.

(55) The house has been sold.

(56) She has been doing the practice (for an hour).

The structure of (55) can be displayed in diagram (57).

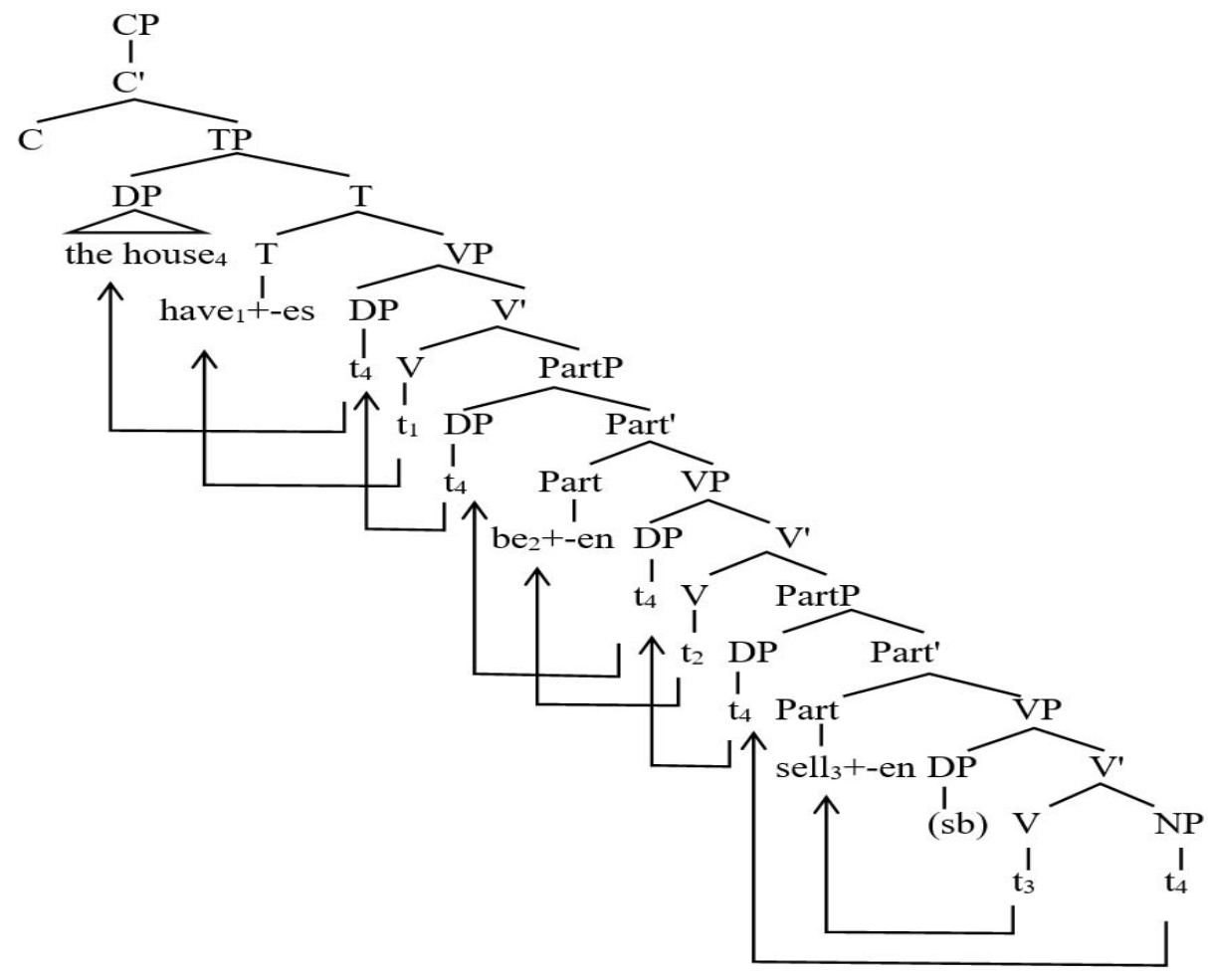

In (57), $\mathrm{T}$-es takes VP headed by have, which in turn takes PartP headed by -en to show the perfect aspect.Have moves to and merges with -es forming has in agreement with Spec/T. The upper Part -en takes VP headed by be, and be moves to and merges with -en forming been. Bealso takes a PartP headed by -en to show the passive voice. The lower Part takes VP headed by sell. Sell, then, moves to and merges with -en forming sold. Finally, the argument the house moves cyclicly from $\mathrm{Spec} / \mathrm{sell}$ to $\mathrm{Spec} / \mathrm{T}$ to meet the subject requirement and to be assigned case.

The D-structure of (56), which is displayed in diagram (58), is the same as (57). 
(58)

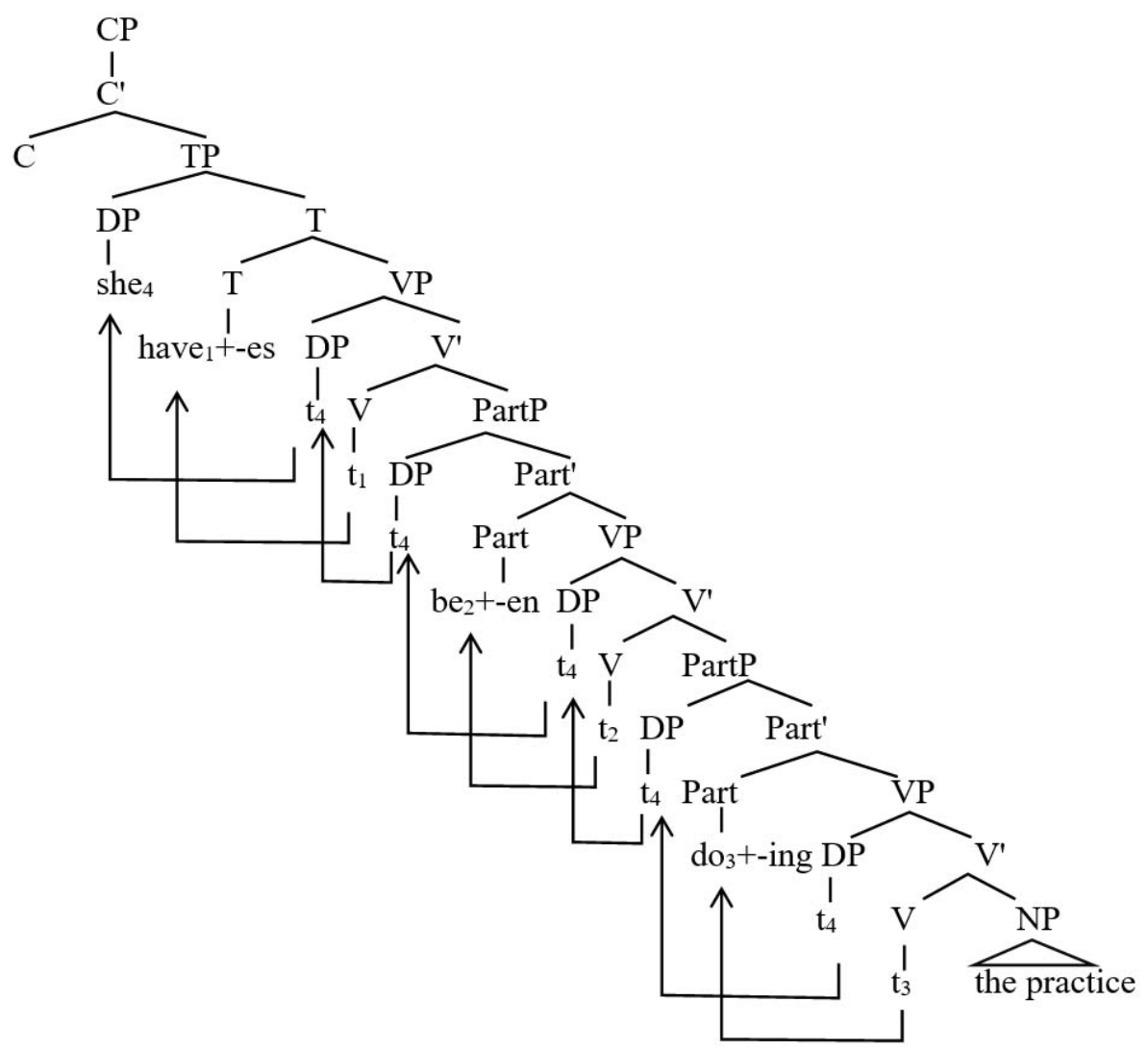

As seen in (58), T -es takes a VP headed by have, and have takes PartP headed by -en to show the perfect aspect. Have moves to and merges with -es forming has in agreement with Spec/T. Part -en takes a VP headed bybe, be takes PartP headed -ing to show the progressive aspect, and -ing takes the VP she do the practice for an hour. Be merges with -en forming been, and domerges with -ing forming doing. Spec/V she, then, moves cyclicly to $\mathrm{Spec} / \mathrm{T}$ to occupy the subject position, leaving a trace $\mathrm{t}_{4}$ in each position it passes.
From the discussion of the structure of (54), (57), and (58), it can be seen that a passive sentence, a progressive sentence, and perfect sentence have the same structure. They are all a CP with $\mathrm{T}$ takes a VP headed by either the auxiliary verb be or the auxiliary verb have, and the auxiliary verb takes a PartP headed by -en or -ing. Part, then, takes a VP as its complement. The S-structures of the sentences are derived through a process of merging of the verbs with the bound morphemes and movement of to fill the sentence subject positions.

\section{Conclusion}

From the discussion above, some conclusions can be made. Firstly, a passive sentence, a progressive sentence, and a perfect sentence as CPs are generated in the same way and have the same D-structure. T takes a VP headed by be or have, and the verb takes a PartP headed by -en or -ing according to the voice or aspect. Part -en or -ing takes as its complement a VP with a full verb as head or beas the head to show a passive voice or progressive aspect if Part does not show a passive voice or progressive aspect.

Secondly, the participle affixes (Part) en and-ingas inflections are present in the generation of a passive, progressive, and 
perfect sentence as a syntactic unit. Part forms a phrase which becomes the complement of be or have and takes a VP as its complement. Part also shares the capacity of $\mathrm{T}$ ( $-e s$ and $-e d$ ) to assign a nominative case to an argument.

Thirdly, or finally, a unified analysis of the English passive voice and progressive and perfect aspects yields a single theory to explain three grammatical processes. The theory observes the principle of economy of derivation and, therefore, may contribute to the explanation of the relative easiness of a child in acquiring his or her mother tongue.

\section{References}

Åfarli, T. A. (1989). Passive in Norwegian and in English. Linguistic Inquiry, 20(1), 1001-108.

Anderson, S. R. (1992). A-Morphous Morphology. Cambride: Cambridge University Press.

Baker, M. C. (2008). The Syntax of Agreement and Concored. Cambridge: Cambridge University Press.

Belliti, A. (2009). Structures and Strategies. New York: Routledge.

Breul, C. (2004). Focus Structure in Generative Grammar: An Ingrated Syntactic, Semantic and Intonational Approach. Amsterdam: John Benjamins B.V.

Breul, C. (2014). The perfect participle paradox: some implications for the architecture of grammar. English Language and Linguistics, 18(3), 449 470.

Bruening, B. (2012). By Phrases in Passives and Nominals. Syntax, 1 - 41.

Bruening, B., \& Tran, T. (2015). The nature of the passive, with an analysis of Vietnamese. Lingua, 165, 133 - 172.

Burton, S., \& Grimshaw, J. (1992). Coordination and VP-Internal Subjects. Linguistic Inquiry, 23(2), 305 - 313.

Caponigro, I., \& Schütze, C. T. (2003). Parameterizing Passive Participle Movement. Linguistic Inquiry, 34(2), $293-308$.
Carstairs-McCarthy, A. (1992). Current Morphology. London: Routledge. London: Routledge.

Carstairs-McCarthy, A. (2002). An Introduction to English Morphology: Words and Their Structure. Edinburg: Edinburgh University Press.

Castillo, C. (2009). On There-Passive Participle Constructions. ATLANTIS. Journal of the Spanish Association of Anglo-American Studies, 31(1),91- 110.

Chomsky, N. (1981). Lectures on Government and Binding: The Pisa Lectures. Dordrecht: Foris Publication.

Chomsky, N. (1986). Knowledge of Language: Its Nature, Origin, and Use. New York: Praeger.

Embick, D. (2004). On the Structure of Resultative Participles in English. Linguistic Inquiry, 35(3), 355 - 392.

Epstein, S. D., \& Seely, T. D. (2006). Derivations in Minimalism. Cambridge. Cambridge: Cambridge University Press.

Fleisher, N. (2006). The Origin of Passive Get. English Language and Linguistics, 10(2), 225 - 252.

Haegeman, L. (2006). Thinking Syntactically. Oxford: Blackwell Publishing.

Jaegli, O. A. (1986). Passive. Linguistic Inquiry, 587 - 622. 
Kallulli, D. (2007). Rethinking the Passive/Anticausative Distinction. Linguistic Inquiry, 38(4), 770 - 780.

Kiparsky, P. (2013). Towards a null theory of the passive. Lingua, 125, 7 - 33 .

Koizumi, M., \& Tamaoka, K. (2010). Psycholinguistic Evidence for the VPInternal Subject Position in Japanese. Linguistic Inquiry, 4(4), 663 - 380.

Koopman, H., \& Sportiche, D. (1991). The Position of Subjects. 85, $211-258$.

Lee, S. A. (2007). Ing forms and the progressive puzzle: a constructionbased approach to English Progressive. Journal of Linguistics, 153 - 195.

Lieber, R. (2009). Introducing Morphology. Cambridge: Cambridge University Press.

McNally, L. (1992). VP Coordination and the VP-Internal Subject Hypothesis. Linguistic Inquiry, 23(2), 336 - 341.

Quirk, R., Greenbaum, S., Leech, G., \& Svartvik, J. (1972). A Grammar of Contemporary English. Essex: Longman Group Ltd.
Radford, A. (2004). English Syntax: An Introduction. Cambridge: Cambridge University Press.

Radford, A. (2009). Analyzing English Sentences. Cambridge: Cambridge University Press.

Radford, A. (2009). Analyzing English Sentences: A Minimalist Approach. Cambridge: Cambridge University Press.

Roy, I. (2013). Nonverbal Predication: Copular Sentences at the SyntaxSemantics Interface. Oxford: Oxford University Press.

Schutze, I. C. (2003). Parameterizing Passive Participle Movement. Linguistic Inquiry 34 (2), 293 - 308.

Shibatani, M. (. (1988). Passive and Voice. Amsterdam/Philadelphia: John Benjamins Publishing Company.

Sportiche, M. (2009). Partitions and Atoms of Clause Structure: Subject, Agreement, Case and Clitics. New York: Routledge.

Zagona, K. (2002). The Syntax of Spanish. Cambridge: Cambridge University Press. 